\title{
Visible persistence and form correspondence in Ternus apparent motion
}

\author{
PETER KRAMER and MICHAEL RUDD \\ Johns Hopkins University, Baltimore, Maryland
}

\begin{abstract}
Visual stimuli remain visible for some time after their physical offset (visible persistence). Visible persistence has been hypothesized to play an important role in determining the pattern of correspondence matching in the Ternus apparent-motion display. In this display, one or more elements reappears in overlapping locations at different times, whereas another element appears alternately to the right or the left of these elements. Usually either the elements are perceived to move coherently as a group (group motion), or one element may be perceived to hop over one or more other elements (element motion). According to the visible-persistence account of the perceptual organization of the Ternus display, element motion is seen when the temporal gap between elements in overlapping locations is small enough to be bridged by visible persistence; if it is not, group motion is seen. We conducted four experiments to test this visible-persistence account. In Experiments 1 and 2, a form correspondence cue (line length) was introduced to bias the visual system toward the element-motion interpretation, while visible persistence was either reduced or eliminated. The element-motion percept dominated despite the elimination of visible persistence. In Experiments 3 and 4, we found that Ternus elements presented without interruption, and thus presumably persisting over time, can be perceived in group motion. Together, the results indicate that visible persistence is neither necessary nor sufficient to account for the pattern of correspondence matches in the Ternus display.
\end{abstract}

Sequences of discrete light flashes, separated by appropriate spatial and temporal intervals, can give rise to a powerful illusion of continuous motion. This apparent motion is the basis for movies, television, and some of the sensory appeal of a nighttime visit to New York's Time Square, Tokyo's Ginza, or the Las Vegas Strip.

In this article, we report the results of some experiments using a classic apparent-motion stimulus known as the Ternus display (Pikler, 1917; Ternus, 1926; Wertheimer, 1912). The version of the display used in our experiments is the historically earliest version and is in fact from Wertheimer (1912; see also Ternus, 1926). Our display is illustrated in Figure 1A. Two elements are presented in Frame 1, followed by a blank interstimulus interval (ISI), and subsequently by two elements in Frame 2 . The positions of the second element in Frame 1 and the first element in Frame 2 overlap spatially. Depending on such factors as the element shape, interelement distance, and the durations of the frames and ISI, the Ternus display gives rise to either of two mutually exclusive motion percepts:

We thank Steven Yantis and Howard Egeth for valuable comments and also Bruno Breitmeyer, Michael Dawson, and Vincent Di Lollo, who were reviewers of this article. We also thank Kathleen Turano for allowing us to perform Experiment 4 in her lab. Correspondence should be addressed to P. Kramer (e-mail: pkramer@casema.net), Mozartlaan 436, 2555 KV Den Haag, The Netherlands, or M. Rudd, University of Washington, Box 351525, Seattle, WA 98195-1525 (e-mail: mrudd@, u.washington. edu).

-Accepted by previous editor, Myron L. Braunstein
(1) Two elements appear to move back and forth in tandem (group motion), or (2) one element hops back and forth over another (element motion).

On the basis of translated excerpts of Ternus's paper (Ellis, 1939, pp. 149-160), another version of the Ternus display has become the most well known and most often used. In this display, three elements, rather than two, are presented in each frame, and two elements, rather than one, overlap spatially across frames. Ternus (1926) credited Pikler (1917) with the invention of this display and for first discovering that the display can give rise to either group or element motion. In the three-element display, either all three elements are perceived to move coherently as a group, or one element is seen to hop back and forth over two other elements. We used the original two-element version of the display in our experiments because it is the simplest, it can also be seen to undergo either group or element motion, it gives rise to all of the same interesting properties that the three-element display gives rise to, and it is subject to the same theoretical interpretations.

Pantle and Picciano (1976) showed that group motion is more probable when the ISI is long and that element motion is more probable when the ISI is short. The probability that an observer will report seeing group motion increases monotonically with ISI. Braddick (1980), Breitmeyer and Ritter (1986a, 1986b), and Casco (1990) argued that the shift from element to group motion with increasing ISI is the result of the visible persistence of the elements displayed at overlapping locations in the two frames. Elements in overlapping locations that are physically differentiated in time by an ISI may not appear to 


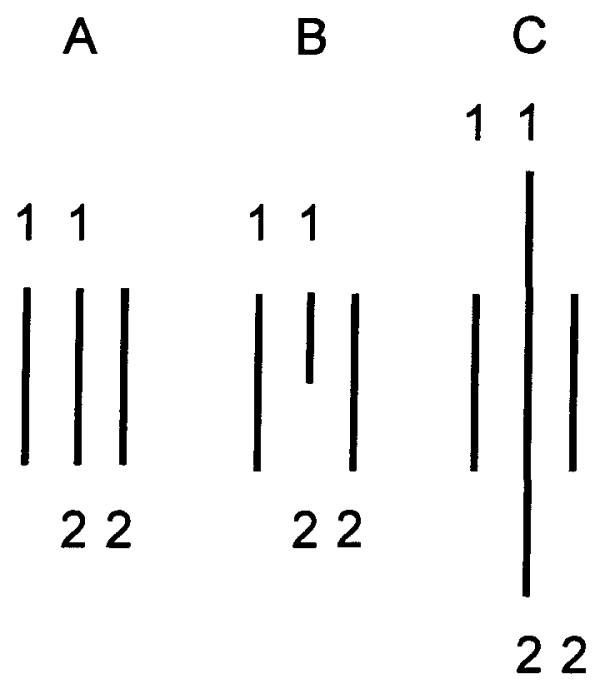

Figure 1. (A) Ternus display (Ternus, 1926; Wertheimer, 1912) with two elements per exposure: Elements labeled "1" appear in Frame 1 and those labeled "2" appear in Frame 2. The middle element appears in both frames. (B) Wertheimer's (1912) version of the display with lines of unequal length. The middle line is reduced in size relative to the middle line in Figure 1A. (C) An adaptation of Wertheimer's display (Figure 1B), in which the middle line is increased in size relative to the middle line in Figure 1B.

be differentiated due to the visible persistence of the Frame 1 elements after their physical offset. If the ISI is small enough to be bridged by visible persistence, then those elements that reappear in the same location in Frame 2 will be perceived as remaining in place, thereby preventing the group-motion percept and yielding the element-motion percept by default. If the ISI is too large for the temporal gap to be bridged by visible persistence, all Frame 1 elements can be seen to disappear before the onset of Frame 2, and are thus freed to undergo motion. Under these conditions, group motion is perceived.

The visible-persistence account is supported by the results of numerous experiments demonstrating that factors known to influence the duration of visible persistence appropriately modulate the proportion of element-motion responses at a particular ISI. For example, it is known that visible persistence decreases with test flash luminance (Bowen, Pola, \& Matin, 1974), decreases with contrast (Bowling \& Lovegrove, 1981; Bowling, Lovegrove, \& Mapperson, 1979), decreases with size and increases with spatial frequency (Bowling \& Lovegrove, 1980; Bowling et al., 1979; Breitmeyer, Levi, \& Harweth, 1981; Corfield, Frosdick, \& Campbell, 1978; Di Lollo \& Woods, 1981; Meyer \& Maguire, 1977), and also decreases with duration (Bowen et al., 1974; Di Lollo, 1977; Efron, 1970a, 1970b). All of these manipulations, when performed on the elements of the Ternus display, increase the percentage of group-motion judgments at a given ISI or, equivalently, shift the ISI at which group motion is reported on $50 \%$ of the trials to smaller values (e.g., Braddick, 1980; Braddick \& Adlard, 1978; Breitmeyer, May, \& Williams, 1988; Breitmeyer \& Ritter, 1986a, 1986b; Petersik \& Pantle, 1979; Ternus, 1926).
Despite the impressive fact that visible persistence explains why all of the above variables interact with ISI to affect the likelihood of perceiving either group or element motion as they do, we will show in this article that the persistence account is neither necessary nor sufficient to account for the perceptual organization of the Ternus display.

It is probably generally recognized, although not always explicitly acknowledged, that visible-persistence accounts must rely on auxiliary hypotheses to account for the complete set of data on the Ternus display. For example, although visible persistence explains why element motion is the dominant percept at short ISIs, it does not explain why the visual system generates the group-motion percept, rather than the element-motion percept, at long ISIs. In our experiments, we relied on the guiding principle that the configural organization of the display at long ISIs depends on Gestalt "grouping" laws, such as grouping by proximity and similarity (Kramer \& Yantis, 1997). We will demonstrate that these laws can influence the perceptual organization of the display at short ISIs as well.

Several theoretical models of the Ternus percept have been presented that combine the persistence mechanism with specific auxiliary hypotheses that instantiate the grouping principles (cf., e.g., Braddick, 1980; Dawson, 1991; Dawson, Nevin-Meadows, \& Wright, 1994; Dawson \& Wright, 1994; Grossberg \& Rudd, 1989, 1992; Pantle \& Picciano, 1976). We will not discuss the merits of these models here, but instead we will focus on one main point: that visible-persistence accounts of Ternus motion need to rely much more on those auxiliary hypotheses than is generally recognized-so much so, in fact, that it might be argued that the visible-persistence mechanism has no real predictive power. Since all of the models rely on visible persistence to one degree or another to explain the perceptual organization of the Ternus display, our results raise problems for all of these proposed accounts of the Ternus percept.

Our basic method was to manipulate other factors than those related to visible persistence that also influence the percentage of group- and element-motion judgments. These other factors were manipulated in such a way that the putative effects of visible persistence were modified and, in some cases, completely overridden. In Experiments 1 and 2, we show that the element-motion percept can be induced by the introduction of form correspondence cues-in particular, by a length difference between the elements in the display - to induce a grouping pattern based on similarity that disambiguates the perceptual organization of the display. Previous studies have shown that many types of form correspondence cues can affect apparent motion (e.g., Mack, Klein, Hill, \& Palumbo, 1989; Orlansky, 1940; Shechter, Hochstein, \& Hillman, 1988; Ullman, 1980; Werkhoven, Sperling, \& Chubb, 1994; Wertheimer, 1912) and the perception of the Ternus display in particular (Kramer \& Yantis, 1997). However, the magnitude of the previously demonstrated form correspondence effects have generally been small. Kramer and Yantis (1997), for example, found that at long ISIs the group-motion percept always dominated, regardless of the 
nature of the form correspondence manipulation. In their study, they equated the areas of the shapes they used, to control for visible-persistence effects. Here we did not control for the effects of visible persistence, but instead pitted visible-persistence effects directly against form correspondence manipulations. This procedure allowed us to employ more radical differences in shape, and thus stronger grouping-by-similarity manipulations than were used in the study by Kramer and Yantis.

Our results demonstrate that (1) visible persistence is neither necessary nor sufficient to explain the percept of element motion in the Ternus display, (2) form correspondence effects can be much more powerful than previously thought, and (3) form correspondence effects are not simply artifacts of visible persistence.

In Experiments 1 and 2, we show that, when form correspondence cues are present to bias the visual system toward the element-motion percept, this percept can dominate, even when other manipulations, designed to reduce or even entirely eliminate visible persistence, are simultaneously performed.

In Experiments 3 and 4, we show that when the ISI is eliminated, so that visible persistence is presumably guaranteed by the fact that some elements remained physically in place on the screen, the group-motion percept can dominate, a result that seems entirely at odds with the persistence account.

\section{EXPERIMENT 1}

The initial inspiration for our study came from the first experiments with the Ternus display that were performed by Ternus's professor, Wertheimer (1912). After demonstrating group motion in a Ternus display with lines of equal length as elements (Figure 1A) (and presumably with a long ISI), Wertheimer reduced the length of some of the lines (Figure 1B). Now only element motion was reported. Since a reduction in the size of an element leads to an increase in visible persistence (Braddick, 1980; Breitmeyer \& Ritter, 1986a, 1986b), it might be argued that Wertheimer's results are mediated by visible persistence. Another possible explanation is that reducing the lengths of some of the elements provides motion correspondence cues that cause the visual system to choose element motion over group motion at long ISIs, on the basis of grouping by similarity.

In Experiment 1, we replicated Wertheimer's (1912) demonstration with the reduced line length manipulation, and also created a Ternus display in which the lengths of some of the lines were increased rather than decreased (Figure 1C). On the hypothesis that Wertheimer's results were due to the introduction of motion correspondence cues, we expected element motion to dominate at long ISIs regardless of whether some of the lines in the display were shortened or lengthened. Such a result cannot be explained as an artifact of visible persistence.

In the same experiment, we introduced the line length motion correspondence cues while simultaneously manip- ulating several factors that have previously been argued to reduce visible persistence and therefore to decrease the probability of element motion: (1) increasing the ISI (Braddick, 1980; Breitmeyer \& Ritter, 1986a, 1986b; Pantle \& Picciano, 1976; Petersik \& Pantle, 1979); (2) presenting the elements as white on gray in Frame 1 and black on gray in Frame 2, with a gray ISI (partial polarity reversal) (Dawson et al., 1994); (3) presenting the elements in white on black in Frame 1 and black on white in Frame 2, with a black ISI (complete polarity reversal) (Pantle \& Picciano, 1976); and (4) introducing random displacements between frames so that no element reappears in the same location (Pantle \& Petersik, 1980).

\section{Method}

Subjects. Eighteen undergraduates from The Johns Hopkins University who were naive with regard to the experimental hypotheses participated for course credit.

Apparatus. An NEC/MultiSync 4 DS monitor with a refresh rate of $72 \mathrm{~Hz}$ was used. The monitor was controlled by an Opta MonaLisa graphics board, installed in a computer with an Intel 486 processing chip.

Stimuli. A completely within-subjects design was used, with three line length conditions, three ISIs, three contrast polarity conditions, a random displacement condition, and a combined contrast polarity and random displacement condition. Ten responses were obtained for each condition. The presentation of the conditions was completely pseudorandomized.

Subjects viewed Ternus displays with two line elements per frame. The elements were either of the same length (Figure 1A) or of a different length (Figure 1C). In the equal-length condition, the two lines were both $5.4^{\circ}$ of visual angle. In the unequal-length condition, they were $5.4^{\circ}$ and $8.2^{\circ}$, or $5.4^{\circ}$ and $15.8^{\circ}$. The widths of the lines were all $.05^{\circ}$ and the viewing distance was $60 \mathrm{~cm}$.

Three different ISIs were used: 0,139 , and $278 \mathrm{msec}$. The frame duration was $153 \mathrm{msec}$. There were three contrast conditions: In the constant-polarity condition, elements were white $\left(61 \mathrm{~cd} / \mathrm{m}^{2}\right)$ on black $\left(.1 \mathrm{~cd} / \mathrm{m}^{2}\right)$ and the interstimulus interval was black. In the partialpolarity-reversal condition, the elements were white on gray $\left(16 \mathrm{~cd} / \mathrm{m}^{2}\right)$ in the odd-numbered exposures, black on gray in the even-numbered exposures, and the screen was uniformly gray during the ISI. In the complete-polarity-reversal condition, the elements were white on black in the odd-numbered exposures, black on white in the even-numbered exposures, and the screen was black during the ISI (following Pantle \& Picciano, 1976). The ambient room illumination was dim.

Two random displacement conditions were used. In a traditional Ternus display, some elements are displaced and some are not; in the random-displacement conditions, an extra random displacement was added to all elements so that none of the elements remained in place. In both conditions, the frames were displaced in random directions over a distance that varied randomly between $0^{\circ}$ and $1.5^{\circ}$ (i.e., the horizontal and vertical components of each displacement were drawn from two independent uniform distributions). In one of the two random-displacement conditions, the contrast polarity was constant (random displacement-constant polarity), whereas in the other it was partially polarity reversed between frames (random displacementpolarity reversed). If visible persistence were necessary for percepts of element motion, then certainly no such percepts would be expected in this condition.

Procedure. Subjects viewed eight successively presented frames (four cycles) of the Ternus display and indicated that they observed "group," "element," or "no motion" after each trial by pushing the appropriate button on a custom-made response box. The experiment lasted $45 \mathrm{~min}$. 

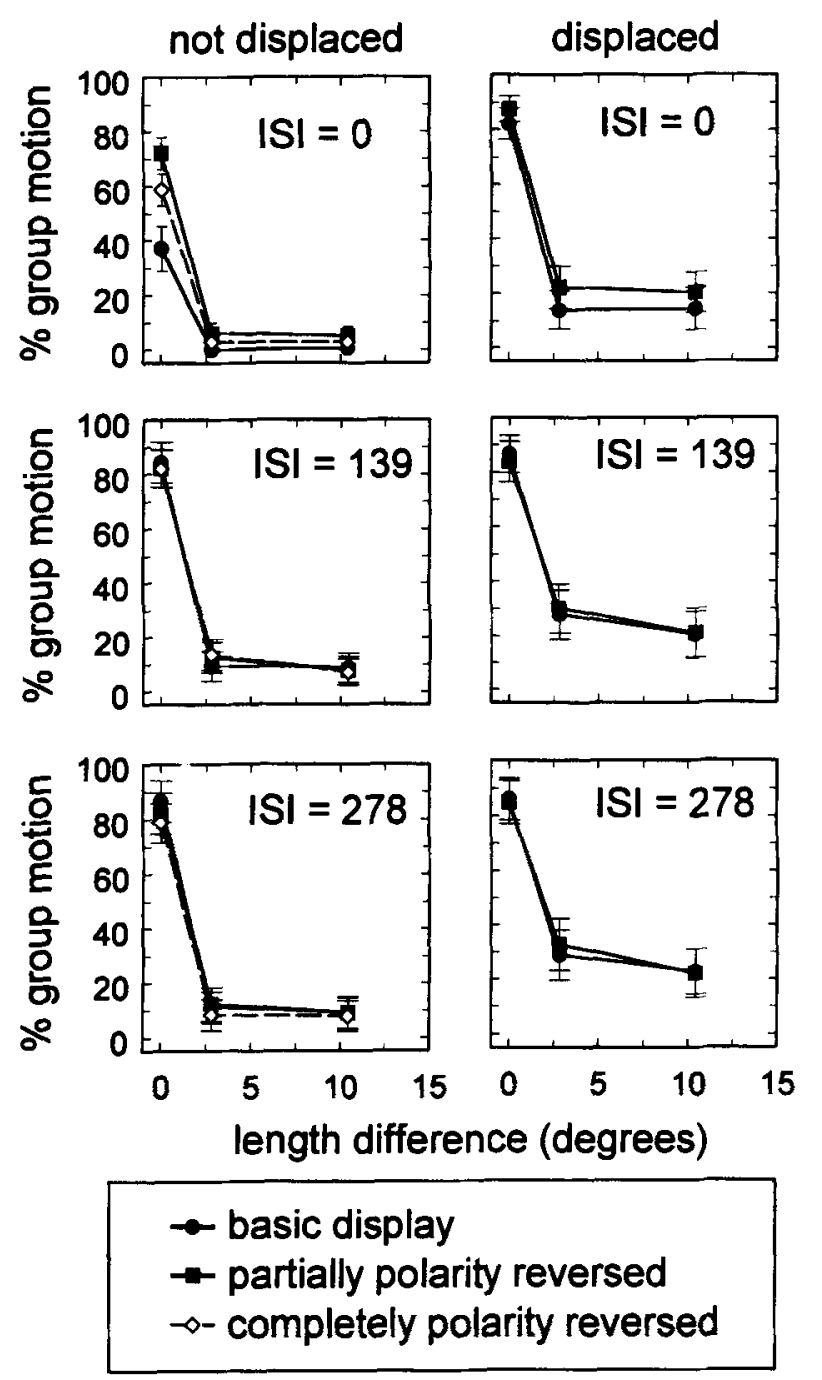

Figure 2. Results of Experiment 1 for interstimulus interval (ISI) $=0,139$, and $278 \mathrm{msec}$. On the left are the results for the conditions that did not involve displacements (with a constant polarity, a partially reversed polarity, or a completely reversed polarity) and on the right are those that did involve displacements (with a constant polarity or a partially reversed polarity). The results show most clearly that element motion was the dominant percept when a difference in line length was introduced among the elements of the Ternus display (Figure 1C) and that this effect occurred under all contrast polarity, displacement, and ISI conditions.

\section{Results and Discussion}

The results are shown in Figure 2. When the elements were equal in length, the group-motion percept dominated. When they were unequal in length, the element-motion percept dominated. The two random-displacement conditions produced more reports of group motion than did the other conditions, but element motion remained the dominant percept, even though none of the elements reappeared in the same location. The equal-line-length display produced more group-motion responses with polarity reversals than without (both when the polarity reversals were partial and when they were complete); with lines of unequal length, however, polarity manipulations had little or no effect (see also Kramer, 1998, for a replication of these results in which the axis of motion was vertical rather than horizontal).

The subjects in Experiment 1 responded under several contrast-polarity and random-displacement conditions while ISI and line-length difference were manipulated in each of these conditions. A multivariate analysis of variance (MANOVA) was performed with ISI and line length difference as the independent variables and with the responses to the levels of the variables involving contrast polarity reversals and random displacements as separate dependent variables.

There was a significant interaction between ISI and linelength difference [Wilks's $\Lambda=.747, F(20,495)=2.272, p=$ $.001]$. Only the univariate $F$ test of the constant-polarity condition reached significance $[F(4,153)=5.035, p=$ $.001]$. In Figure 2, it can be observed that in the constantpolarity condition (filled circles), the effect of line-length difference was less pronounced at ISI $=0$ than at ISI $=139$ or ISI $=278$.

There was a main effect of ISI [Wilks's $\Lambda=.739$, $F(10,298)=4.875, p<.001]$. The results of univariate $F$ tests were as follows: There was a significant effect of ISI in the constant-polarity condition $[F(2,153)=14.795$, $p<.001]$ and in the complete-polarity-reversal condition $[F(2,153)=4.827, p=.009]$. In Figure 2, it can be seen that in those two conditions (indicated by the filled circles and the open diamonds, respectively), there were fewer group-motion responses at ISI $=0$ than at ISI $=139$ or ISI $=278$. The effect of ISI was not significant in the random-displacement-constant-polarity condition, the partial-polarity-reversal condition, or the randomdisplacement-polarity-reversal condition.

Finally, there was a main effect of line-length difference [Wilks's $\Lambda=.313, F(10,298)=23.5, p<.001$ ]. In Figure 2 , it can be seen that this effect is the most important one. The results of univariate $F$ tests show that there were significant effects of line-length difference in all conditions (there were many more group-motion responses when the difference between the line lengths in the Ternus display was zero than when it was not). An alpha level of $p<.001$ was used in all conditions, and the $F$ statistics were as follows: constant-polarity condition $[F(2,153)=$ $117.499]$, complete-polarity-reversal condition $[F(2,153)=$ 151.527], random-displacement-constant-polarity condition $[F(2,153)=66.414]$, partial-polarity-reversal condition $[F(2,153)=148.629]$, and random-displacementpartial-polarity-reversal condition $[F(2,153)=57.385]$.

According to past predictions based on the visiblepersistence account (Braddick, 1980; Braddick \& Adlard, 1978; Breitmeyer et al., 1988; Breitmeyer \& Ritter, 1986a, 1986b; Casco, 1990; Grossberg \& Rudd, 1989, 1992; Ritter \& Breitmeyer, 1989), more group motion is expected at longer ISIs, and with displacements between exposures and polarity reversals. These predictions are clearly inconsistent with our results, which demonstrate that (1) form correspondence cues (similarity) can have a powerful effect on the perceptual organization of the Ternus display, 
(2) the effects of form correspondence cannot be alternatively explained in terms of visible-persistence effects, and (3) correspondence cues determine the percept of the Ternus display when visible persistence is absent, or at least very weak - when polarity reversals prevent the elements from visibly persisting from one frame to the next, or when visible persistence cannot link elements in Frame 1 and Frame 2 appropriately, due to random displacements between frames.

\section{EXPERIMENT 2}

In Experiment 2, Frame 1 of Figure $1 \mathrm{C}$ was shown to one eye and Frame 2 to the other (dichoptic presentation; Shipley, Kenney, \& King, 1945). In previous research, more group motion was found with dichoptic presentation than with binocular presentation (Pantle \& Picciano, 1976). The effect has been attributed to reduced visible persistence (Braddick, 1980; Ritter \& Breitmeyer, 1989).

\section{Method}

Subjects. Three undergraduates from The Johns Hopkins University, naive with respect to the experimental hypotheses, participated for course credit. P.K. and M.R. also served as subjects.

Apparatus. Stimuli were displayed on a Seiko Instruments CM1450-C color monitor controlled by a Video Seven VRAM VGA graphics card. A Vision Research Graphics PC Stercoscope was used that alternates displays between the left and the right eyes at $30 \mathrm{~Hz}$ by appropriately opening and closing liquid crystal shutters on goggles worn by the subject.

Stimuli and Procedure. The stimuli (Figure 1C) were presented dichoptically. The short lines were $.7^{\circ}$ high and the long ones $1.4^{\circ}$. All lines were about $.08^{\circ}$ wide and white $\left(83^{\circ} \mathrm{cd} / \mathrm{m}^{2}\right)$ on black $\left(.1^{\circ} \mathrm{cd} / \mathrm{m}^{2}\right)$. The interelement distance was $.24^{\circ}$. Viewing distance was $45 \mathrm{~cm}$. The exposure duration of each frame was $300 \mathrm{msec}$ and the ISI was also $300 \mathrm{msec}$. Ambient illumination was dim. Subjects were asked to report their percepts verbally after each of a total of 10 trials. The experiment lasted $10 \mathrm{~min}$.

\section{Results and Discussion}

Contrary to earlier findings with dichoptic Ternus displays (Braddick, 1980; Pantle \& Picciano, 1976; Ritter \& Breitmeyer, 1989), in our experiment with lines of unequal length, group motion was completely eliminated, even with an ISI and exposure duration of $300 \mathrm{msec}$ (conditions that would be certain to produce group motion with lines of equal length). Our results can therefore not be explained on the basis of visible persistence; all subjects perceived element motion exclusively, even when persistence could not reasonably be expected to bridge the ISI, based on typical estimates of the duration of visible persistence (e.g., Coltheart, 1980). Form correspondence cues influenced the subjects to report element motion, even when visible persistence was of insufficient duration to force the element-motion percept. Consistent with the results of Experiment 1, Experiment 2 demonstrated that form correspondence effects can exert a powerful influence on the Ternus percept that cannot be attributed to an artifact of visible persistence, because persistence was either completely absent or very weak.

\section{EXPERIMENT 3}

In Experiment 3, we eliminated the ISI in the standard Ternus display of Figure 1A so that one of the elements was continuously displayed in the same location throughout both frames of the display. According to the visiblepersistence account of the Ternus percept, element motion occurs whenever a visible trace of the stationary element persists across the ISI (e.g., Breitmeyer \& Ritter, $1986 \mathrm{a}, 1986 \mathrm{~b}$ ). In the absence of an ISI, there is no gap to be bridged and element motion should be perceived exclusively.

The purpose of this experiment was to challenge the visible-persistence account by showing that a large percentage of group-motion judgments can be obtained with an ISI of zero. The strength of grouping by proximity increases with decreases in interelement distance and the probability of reporting group motion in the Ternus paradigm with elements of equal length decreases with interelement distance (Petersik \& Pantle, 1979; Ternus, 1926 , p. 116, note 1). To maximize the chances of observing group motion, we therefore chose a small interelement distance.

\section{Method}

Subjects. Five subjects from The Johns Hopkins University participated ( 2 undergraduates and 2 graduate students, all naive with respect to the experimental hypotheses, and P.K.). All subjects were volunteers and 1 undergraduate was paid $\$ 1$ for his participation.

Apparatus and Stimuli. The same equipment was used as in Experiment 1. A Ternus display with equal length elements was employed (Figure 1A). Frame durations were long ( $458.3 \mathrm{msec})$, but the ISI was zero. One of the lines remained on the screen for the entire trial. The other appeared at the same time to the left of it, for $458.3 \mathrm{msec}$, followed immediately by another line to the right of it, also for $458.3 \mathrm{msec}$, after which the line on the left appeared again, and so on. All lines were $1.7^{\circ} \mathrm{high}$ and $.03^{\circ}$ wide, and were white $\left(61 \mathrm{~cd} / \mathrm{m}^{2}\right)$ on black $\left(.1 \mathrm{~cd} / \mathrm{m}^{2}\right)$. Short interelement distances were used (.09 in the narrow condition, $.17^{\circ}$ in the wide condition) in order to bias the subject to report group motion. The viewing distance was $1 \mathrm{~m}$. The ambient illumination was dim.

Procedure. Subjects viewed 10 trials in pseudorandom order: five in the narrow condition, five in the wide condition, and reported their percepts verbally after each trial. The experiment lasted about $5 \mathrm{~min}$.

\section{Results and Discussion}

All 5 subjects reported group motion exclusively in the narrow condition. Four of the subjects also reported only group motion in the wide condition. The 1 subject who did report element motion in the wide condition nevertheless reported group motion in three of the five trials.

Although one of the two lines of the Ternus display remained on the screen for the entire trial, it was perceived to move. Informal observation suggests that even if this line stays on the screen during the entire experiment, it is still perceived to move. It often required careful scrutiny close to the screen to convince subjects that no programming error was involved.

Our results may be regarded as a form of motion capture, a phenomenon in which stationary elements in a 
field of containing displaced elements are perceived to move along with those that are displaced (Ramachandran \& Cavanagh, 1987; Ramachandran \& Inada, 1985).

In any event, the results of Experiment 3 show that group motion can be perceived almost exclusively in a Ternus display with no ISI, a fact that is at odds with previous claims based on the visible-persistence account of the Ternus percept.

\section{EXPERIMENT 4}

Experiment 4 was performed in response to the concern of a reviewer that the large percentage of group-motion judgments in Experiment 3 might have been due to an artifact of our computer display technique. In Experiment 3, successive frames were generated by a computer program that entails the swapping back and forth of visual pages. This technique allows for a careful control over presentation times and the synchronization of those with screen refreshes. However, if the visual pages were not swapped at the right moment, the elements that were supposed to be continuously on the screen might have been interrupted for very brief intervals. No such interruptions were visible, suggesting that even if small temporal gaps were present, these must have been bridged by visible persistence. However, to ensure that group motion can indeed be observed in a Ternus display with no ISI, we repeated Experiment 3 with a computer program that did not involve page swapping. The stationary element was presented throughout both frames and the "hopping" element was presented to the left of the stationary element in Frame 1 and to the right of it in Frame 2. The presentation times could not be controlled as carefully in this experiment as in the previous one, which employed page swapping, but one can be confident that those stimuli that were supposed to be continuously present were indeed continuously present.

\section{Method}

Subjects. Two postdoctoral fellows and 1 employee of The Johns Hopkins Medical School volunteered as subjects in the experiment without pay. Two additional undergraduate students of The Johns Hopkins University participated as well; 1 of them was paid $\$ l^{*}$ for participating, and the other 1 participated without pay. All subjects were naive with respect to the experimental hypotheses.

Because the interelement distance was small, as in Experiment 3, standard acuity charts were used to ensure that all subjects had sufficient acuity (at least 20/20, or corrected to 20/20).

Apparatus. A Dell PC computer with an IMAGRAPH highresolution graphics board $(1,280 \times 1,024 \times 8$ bits $)$ was used.

Stimuli. The stimuli were similar to those presented in Experiment 3 (Figure 1A), with approximately the same height and width. The interelement distance was $.15^{\circ}$. The viewing distance was $72 \mathrm{~cm}$. The ISI was always zero and the frame durations were about $400 \mathrm{msec}$. The stimuli were white $\left(95.0 \mathrm{~cd} / \mathrm{m}^{2}\right)$ on black $\left(.4 \mathrm{~cd} / \mathrm{m}^{2}\right)$. The ambient room illumination was $\mathrm{dim}$.

Procedure. Subjects viewed 10 trials. After each trial, subjects were asked to report verbally whether they saw "group motion," "element motion," or "no motion." At the end of the experiment, they were also asked how many lines per frame they had seen during a trial to ensure that the two lines presented in each frame had been adequately resolved. All subjects reported having seen two lines per frame. The experiment lasted $5 \mathrm{~min}$.

\section{Results and Discussion}

The results confirm those of Experiment 3. Group motion was observed in this Ternus display with zero ISI, contrary to predictions based on visible persistence. One subject reported element motion twice out of a total of 10 trials; all other subjects reported group motion exclusively. The "no-motion" option was not used by any of the subjects in any of the trials.

\section{GENERAL DISCUSSION}

The implications of our results are twofold. First, they emphasize the importance of form correspondence, or grouping by similarity, in determining the perceptual organization of the Ternus phenomenon. Second, they demand a reevaluation of the role of visible persistence in determining the perceptual organization of the Ternus percept. We will discuss these two issues separately in the two subsections that follow.

\section{Form Correspondence Effects}

A recurring theme in the history of apparent-motion research concerns the degree to which two successive visual stimuli must match in form in order to give rise to the percept of a single element undergoing motion (form correspondence). The results of many experiments, employing diverse stimuli ranging from geometric figures to Gabor patches, indicate that apparent motion can be observed between dissimilar shapes as well as similar ones. This has led many researchers to conclude that form correspondence has little or no role in the computation of apparent motion (e.g., Dawson, 1991; Kolers, 1972; Kolers \& Pomerantz, 1971; Navon, 1976; Petersik, 1984; Werkhoven, Sperling, \& Chubb, 1993, 1994).

Although these experiments demonstrate that complete form correspondence is not required in order to generate apparent motion, they do not rule out the possibility that the visual system is nevertheless sensitive to form correspondence cues (see, e.g., Dawson et al., 1994; Mack et al., 1989; Orlansky, 1940; Shechter et al., 1988; Ullman, 1980; Werkhoven et al., 1994). Form correspondence effects seem to exert their greatest effect in situations where two or more motion percepts are possible, as in the bistable Ternus display investigated here, suggesting that the motion system is capable of using form correspondence cues, when available, to disambiguate a complex motion scene.

In the context of the Ternus display, in particular, previous research suggested that form correspondence effects were rather weak relative to the effects related to visible persistence. We hypothesized that, depending on the particular choice of forms, form correspondence effects could be more powerful than the putative effects of visible persistence. By using several different manipulations to reduce or eliminate persistence in Experiments 1 and 2 , we first demonstrated that in the absence of visible persistence, form correspondence cues completely determine the Ternus percept. In Experiments 3 and 4, we showed that when the elements in the Ternus display are similar in 
form and close in proximity, group motion is seen where the visible persistence predicts that element motion should be observed.

Altogether, our results demonstrate not only that the effects of form correspondence on apparent motion can be much more powerful than has often been claimed, but also (in the context of the Ternus display) that these effects cannot be artifacts of visible persistence and that they can override any effects of persistence that may exist.

\section{Whither the Visible-Persistence Account of Ternus?}

In Ternus displays that give rise to element motion, visible persistence has often been assumed to bridge the ISI, to link the elements that appear in the same location in different frames, and to cause them to appear stationary. Kramer and Yantis (1997) showed that form correspondence cues designed to bias the Ternus display toward element motion also need to be taken into account. In their study, however, group motion dominated at large ISIs, even in the presence of form correspondence cues that would have been expected to support element motion. Thus, the results of Kramer and Yantis do not rule out the hypothesis that visible persistence across the ISI is a necessary condition for obtaining element motion.

Our Experiments 1 and 2, however, demonstrate that visible persistence is not required to produce element motion. In many of the conditions in Experiment 1, visible persistence was either completely absent or at least very weak, due to the use of long ISIs, contrast polarity reversals, and random displacements between frames. And in Experiment 2, visible persistence was at least very weak, due to the use of long frame durations, long ISIs, and a dichoptic mode of presentation. Nevertheless, in both experiments, element motion was the dominant percept.

The results of Experiments 3 and 4 are even more troublesome for the persistence account. Here, one of the elements was physically present throughout both frames of the Ternus display and there was no ISI. This should have ensured a visibly persisting signal and, according to the persistence account of Ternus, forced the element-motion percept. Instead, group motion was observed almost exclusively.

The persistence theory has been very successful at accounting for the influence of a large number of factors (element duration, contrast, spatial frequency, etc.) on the perceptual organization of the Ternus display. It therefore seems worthwhile to consider possible alterations of, and alternatives to, the persistence account that could preserve the original explanatory power of the persistence theory and also accommodate our experimental results. We will suggest three possible theoretical responses to our findings. The first entails a modest change in the visiblepersistence account. The second attempts to account for our results with alternative models of persistence, or temporal integration, that have been proposed within the visible-persistence literature. The third approach is to conceive of the integration of successive elements in the Ter- nus display as a form of temporal grouping subject to Gestalt grouping principles.

The first response is the following. When pairs of Ternus elements are presented very close to one another, as in Experiments 3 and 4, it is possible that they are detected by a single neural unit-for example, a V1 receptive field - that responds directly to the pair, rather than to the separate individual elements. If that were true, the receptive field location of the neuron most strongly stimulated by the pair of elements presented in Frame 2 would differ from that of the neuron most strongly stimulated by the pair of elements presented in Frame 1. This shift in the centroid of stimulation between frames could lead to a motion signal, even at zero ISI, which would be interpreted as group motion.

This theory essentially suggests that there is a special grouping mechanism that acts only when the interelement distance is small. It would presumably not be the same mechanism that computes long-range correspondence matches, since these have very different characteristics, being relatively impervious, for example, to contrast reversals and random displacements between frames.

A complication for this theory is that the individual elements remain clearly distinguishable. Even if there are neural units that respond to pairs of elements, there must also be units that respond to the elements individually. Thus, separate pathways would be required for the computation of form and motion. There is neurophysiological evidence for separate motion and form pathways, associated with the magnocellular and parvocellular systems, respectively (see, e.g., Wandell, 1995, for a review). Although motion perception does not strictly require an intact magnocellular pathway (Merigan, Byrne, \& Maunsell, 1991; see also Wandell, 1995), the magnocellular pathway may nevertheless have mediated the percept of group motion in Experiments 3 and 4 by basing a motion computation on groups of elements rather than on individual ones. The parvocellular pathway (form system) could simultaneously enable us to resolve the individual elements.

A second possible response to our findings is to retain the assumption that the perceptual organization of the Ternus display depends on whether the first and second frames of the display are perceptually integrated or not, but to reject the assumption that perceptual integration is ensured by the uninterrupted presentation of an element across both frames of the display. In Experiments 3 and 4, one of the elements was continuously presented, yet group motion was perceived. To explain this result on the basis of a persistence mechanism, one must assume that a continuous element does not necessarily persist in the "eyes" of the motion system, but that it may in fact fade before the offset of the first frame. If the actually continuous element were perceived only transiently by the motion system, then its apparent offset would allow for it to contribute to a group-motion percept.

Let us assume for the moment that the hypothesis is correct - that the neural representation of the element 


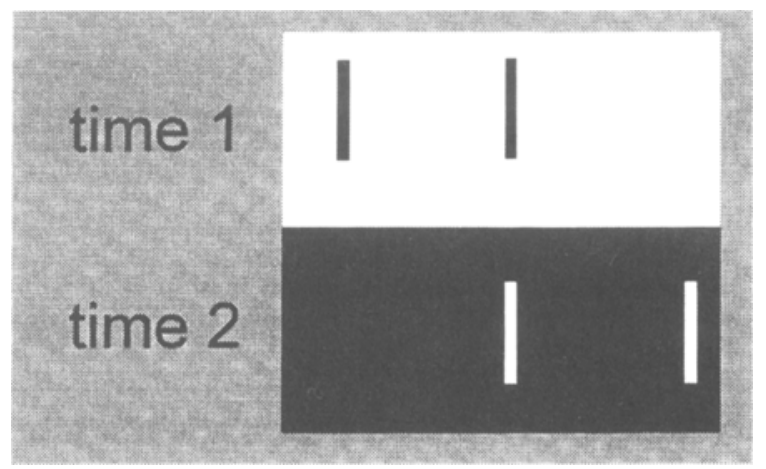

Figure 3. A reversed-polarity Ternus display: Two elements are presented at Time 1 and two at Time 2; one of the elements in Frame 1 appears in a location that overlaps with the location of one of the elements in Frame 2. Grouping over time is weakened by polarity reversals, but grouping in space is unaffected.

that is continuously presented throughout the two frames is transient and may fail to persist for the physical duration of the element. There are then two possibilities: Either this transient neural representation is the basis of the visible percept of the element, or it is an invisible representation that may be used by the brain for the purpose of computing motion, and perhaps more generally, for either temporally grouping or segregating successive events. Either of these two possibilities might form the basis for a model of the perceptual organization of the Ternus display, but it should be noted that the laws that govern visible persistence and those that govern invisible persistence are not necessarily the same (Coltheart, 1980).

Although the hypothesis that visible persistence may run its course before the actual physical offset of a stimulus may seem at odds with phenomenal experience, two different models of visible persistence have been proposed that allow for this possibility (Di Lollo, 1980; Di Lollo \& Dixon, 1988; Loftus, Duncan, \& Gehrig, 1992). Both models assume that visible persistence corresponds to a neural response that begins at stimulus onset and lasts for a constant period that is independent of the stimulus duration. In Experiments 3 and 4, the frame durations were long and, according to these models, visible persistence may then have tapered off. However, this theory does not provide a mechanism for generating onset signals at the locations of both elements in Frame 2, which is difficult to reconcile with the fact that group motion is perceived.

Di Lollo and colleagues (Di Lollo, Hogben, \& Dixon, 1994; Dixon \& Di Lollo, 1994; cf. Francis, 1996) have also introduced an alternative model of temporal integration based on a temporal correlation of visual patterns presented in successive frames. The model produces a visual response to an element presented in Frame 1, another visual response to an element presented in Frame 2, and then correlates samples from those two visual responses to determine the strength of temporal integration. However, in Experiments 3 and 4, one of the elements presented in Frame 1 remained on the screen and did not have a new onset in Frame 2 and hence presumably no second visual response that could have been used for temporal integration.
Even if the results of our Experiments 3 and 4 could be accounted for by a modified persistence theory, this theory would need to be augmented by additional mechanisms, such as Gestalt grouping principles, in order to account for the results of Experiments 1 and 2. Dawson and Wright (1994) introduced a model — a parallel distributed network-based on visible persistence with such additional organizational principles explicitly specified and implemented in the form of soft "constraints." The model does not provide for the possibility of group motion at zero ISI, but perhaps it could be modified to do so.

In any case, our results demonstrate that any such hybrid model needs to rely much more on factors other than visible persistence than previous evidence has suggested. Once this is acknowledged, one may wonder whether some of the effects that have previously been ascribed to persistence can be alternatively explained by the "auxiliary" factors. In the third theoretical response to our findings, we consider the possibility that grouping principles may account for the entire corpus of Ternus motion effects, without the need to invoke visible persistence as even a partial explanatory mechanism.

Kramer and Yantis (1997) argued that there may be tradeoff between perceptual grouping in space and in time that determines the perceptual organization of the Ternus display. Their spatiotemporal grouping account predicts more group motion when the grouping in space is strengthened or when the grouping over time is weakened. Like the visible-persistence account, the spatiotemporal grouping account predicts more group motion when long rather than short ISIs are employed (Pantle \& Picciano, 1976), and it also predicts more group motion when short rather than long interelement distances are used (Petersik \& Pantle, 1979; Ternus, 1926, p. 116, note 1).

Now consider a reversed-polarity Ternus display (Figure 3). The elements presented at the same location but at successive moments in time do not match in contrast polarity; hence grouping over time is weakened relative to that in a constant-polarity display. The elements presented at the same moment in time do match in contrast polarity and thus the grouping in space is neither diminished nor enhanced relative to the constant-polarity display. Therefore, the spatiotemporal grouping account predicts fewer element-motion responses in a reversedpolarity display than in a constant-polarity display. The visible-persistence account makes the same prediction and the data support it (Dawson et al., 1994; Kramer, 1998; Pantle \& Picciano, 1976). ${ }^{1}$ However, when form correspondence cues are introduced that reduce the grouping in space (by introducing a within-frame dissimilarity, as in Figure 1C) but leave the grouping over time unaffected, then the spatiotemporal grouping account correctly predicts an increase in element-motion responses. The visible-persistence account alone cannot explain this effect.

Similarly, displacing elements in a Ternus display that are ordinarily presented in overlapping locations weakens temporal grouping between the successive elements (by reducing their spatial proximity across the two frames) 
and thus increases the probability of a group-motion response (Pantle \& Petersik, 1980). However, if the grouping in space is weakened even more by introducing strong form correspondence cues (i.e., within-frame dissimilarity), then the element-motion percept dominates again (as found in Experiment 1). Once again, a visible-persistence account would require auxiliary hypotheses to account for the percept of element motion with nonoverlapping elements.

It is not clear how grouping would account for effects of frame duration, element contrast, and element size or spatial frequency, if at all. Since the ability to account for these effects has been cited as potent evidence for the visible-persistence theory, we now reexamine this evidence. First, it is not clear how the visible-persistence account can explain the effect of frame duration; it went awry in Experiments 3 and 4, where Ternus displays with long frame durations were perceived in group motion, but where there was no ISI and no temporal gap that visible persistence could have failed to bridge. Second, the visible-persistence account does provide explanations for the effects of the manipulations contrast, and element size or spatial frequency. However, given that it is difficult to explain our data with a visible-persistence account, it is worth considering the possibility that the consistent effects of these manipulations on both visible persistence and Ternus apparent motion do not imply a causal connection between persistence and the Ternus motion percept.

Stimulus factors that decrease visible persistence (high contrast, large size, low spatial frequency) increase the proportion of Ternus group-motion responses. However, the same stimulus factors increase the likelihood of stereoscopic fusion in completely static displays (Burt \& Julesz, 1980a, 1980b; Julesz \& Miller, 1975; Richards \& Kay, 1974; Schor \& Wood, 1983; Sperling, 1970; Tyler, 1983,1990 ), even though there is no reason to believe that these effects are mediated by visible persistence. Similarly, there are more transient cells in the periphery than in the fovea, and visible persistence is shorter in the periphery than in the fovea (Di Lollo \& Hogben, 1985). Consistent with the visible-persistence account, more group motion is observed with peripheral than with foveal presentation (Breitmeyer \& Ritter, 1986b; Ternus, 1926; Ullman, 1979). However, peripheral presentation also enhances stereoscopic fusion in static displays (Julesz, 1971; Rose \& Blake, 1988), although there is again no reason to believe that visible persistence mediates this effect. Thus, the mere fact that there is a consistent pattern of correlations between visible persistence and Ternus element motion does not necessarily imply a causal relationship between the two.

\section{Conclusion}

We have shown that visible persistence is neither a necessary nor a sufficient condition for producing Ternus element motion and that its putative effects on the perceptual organization of the Ternus display can be completely overridden by other factors. We have also shown that form correspondence effects are more powerful than previously acknowledged and that they cannot be alternatively explained as an artifact of visible persistence.

We have considered a modification of the traditional visible-persistence account that assumes that two elements that are close together could give rise to just one neural response in a motion system even when they can be distinguished as separate by a form system. It could explain the results of Experiments 3 and 4. Models of visible persistence that allow for the visible trace to decay before the physical offset of an element may also help to explain the results of these two experiments. We have also considered an alternative account of the perceptual organization of the Ternus display based on Gestalt grouping principles.

Finally, we discussed some effects on Ternus apparent motion that are not explained by the spatiotemporal grouping account, but have previously been taken as evidence for the visible-persistence account, such as the effects of contrast and element size or spatial frequency and mode of presentation (peripheral vs. foveal). We have argued, however, that despite the intuitive appeal of the model that explains these effects in terms of persistence, the pattern of correlations between visible persistence and apparent motion can nevertheless not necessarily be taken as evidence for the visible-persistence account, because the pattern of correlations extends to stereoscopic fusion in completely static displays and visible persistence is not likely to have played a causal role there.

\section{REFERENCES}

Bowen, R. W., Pola, J., \& Matin, L. (1974). Visual persistence: Effects of flash luminance, duration and energy. Vision Research, 14, 295-303.

Bowling, A., \& Lovegrove, W. (1980). The effect of stimulus duration on the persistence of gratings. Perception \& Psychophysics, 27, 574-578.

Bowling, A., \& Lovegrove, W. (1981). Two components of visual persistence: Effects of orientation and contrast. Vision Research, 21, 1241-1251.

Bowling, A., Lovegrove, W., \& Mapperson, B. (1979). The effect of spatial frequency and contrast on visual persistence. Perception, 8 , 529-539.

BRADDICK, O. J. (1980). Low-level and high-level processes in apparent motion. Philosophical Transactions of the Royal Society: Series B, 290, 137-151.

Braddick, O. J., \& AdLARD, A. (1978). Apparent motion and the motion detector. In J. C. Armington, J. Krauskopf, \& B. R. Wooten (Eds.), Visual psychophysics and psychology (pp. 417-426). San Diego: Academic Press.

Breitmeyer, B. G., LeVI, D. M., \& HARWeTH, R. S. (1981). Flickermasking in spatial vision. Vision Research, 21, 1377-1385.

Breitmeyer, B. G., May, J. G., \& Williams, M. C. (1988). Spatial frequency and contrast effects on percepts of bistable stroboscopic motion. Perception \& Psychophysics, 44, 525-531.

Breitmeyer, B. G., \& RitTER, A. D. (1986a). The role of visual pattern persistence in bistable stroboscopic motion. Vision Research, 26, $1801-1806$.

Breitmeyer, B. G., \& Ritter, A. D. (1986b). Visual persistence and the effects of eccentric viewing, element size, and frame duration on bistable stroboscopic motion percepts. Perception \& Psychophysics, 39, 275-280.

BurT, P., \& Julesz, B. (1980a). A disparity gradient limit for binocular fusion. Science, 208, 615-617.

BurT, P., \& JULESZ, B. (1980b). Modification of the classical notion of Panum's fusional area. Perception, 9, 671-682. 
CASCo, C. (1990). The relationship between visual persistence and event perception in bistable motion display. Perception, 19, 437-445.

Coltheart, M. (1980). Iconic memory and visible persistence. Perception \& Psychophysics, 27, 183-228.

Corfield, R., Frosdick, J. P., \& Campbell, F. W. (1978). Grey-out elimination: The roles of spatial waveform, frequency and phase. $V i$ sion Research, 18, 1305-1311.

Dawson, M. R. W. (1991). The how and why of what went where in apparent motion: Modeling solutions to the motion correspondence problem. Psychological Review, 98, 569-603.

Dawson, M. R. W., Nevin-Meadows, N., \& Wright, R. D. (1994). Polarity matching in the Ternus configuration. Vision Research, 34, 3347-3359.

Dawson, M. R. W., \& WRIGHT, R. D. (1994). Simultaneity in the Ternus configuration: Psychophysical data and a computer model. Vision Research, 34, 397-407.

Di Lollo, V. (1977). Temporal characteristics of iconic memory. $\mathrm{Na}$ ture, 267, 241-243.

Di LOLLO, V. (1980). Temporal integration in visual memory. Journal of Experimental Psychology: General, 109, 75-97.

Di Lollo, V., \& Dixon, P. (1988). Two forms of persistence in visual information processing. Journal of Experimental Psychology: Human Perception \& Performance, 14, 671-681.

Di Lollo, V., \& Hogren, J. H. (1985). Suppression of visible persistence. Journal of Experimental Psychology: Human Perception \& Performance, 11, 304-316.

Di Lollo, V., Hogben, J. H., \& Dixon, P. (1994). Temporal integration and segregation of brief visual stimuli: Patterns of correlation in time. Perception \& Psychophysics, 55, 373-386.

Di LolLO, V., \& WooDs, E. (1981). Duration of visible persistence in relation to spatial frequencies. Journal of Experimental Psychology, 4, 754-769.

Dixon, P., \& Di Lollo, V. (1994). Beyond visible persistence: An alternative account of temporal integration and segregation in visual processing. Cognitive Psychology, 26, 33-63.

EFRON, R. (1970a). Effect of stimulus duration on perceptual onset and offset latencies. Perception \& Psychophysics, 8, 231-234.

EFrON, R. (1970b). The relationship between the duration of a stimulus and the duration of a perception. Neurophysiologia, 8, 37-55.

Ellis, W. D. (1939). A sourcebook of Gestalt psychology. New York: Humanities Press.

FRANCIS, G. (1996). Cortical dynamics of visual persistence and temporal integration. Perception \& Psychophysics, 58, 1203-1212.

GrossBerg, S., \& RUDD, M. E. (1989). A neural architecture for visual motion perception: Group and element apparent motion. Neural Networks, 2, 421-450.

Grossberg, S., \& RUDD, M. E. (1992). Cortical dynamics of visual motion perception: Short-range and long-range apparent motion. Psychological Review, 99, 78-121.

JULESZ, B. (1971). Foundations of cyclopean perception. Chicago: University of Chicago Press.

JULESZ, B., \& MILlER, J. E. (1975). Independent spatial-frequencytuned channels in binocular fusion and rivalry. Perception, 4, 125143.

Kolers, P. A. (1972). Aspects of motion perception. Oxford: Pergamon.

Kolers, P. A., \& PomerantZ, J. R. (1971). Figural change in apparent motion. Journal of Experimental Psychology, 87, 99-108.

KRAMER, P. (1998). Linking correspondence matching in stereopsis and apparent motion. Doctoral dissertation, Johns Hopkins University.

Kramer, P., \& Yantis, S. (1997). Perceptual grouping in space and time: Evidence from the Ternus display. Perception \& Psychophysics, 59, 87-99.

Loftus, G. R., Duncan, J., \& Gehrig, P. (1992). The time course of perceptual information that results from a brief visual presentation. Journal of Experimental Psychology: Human Perception \& Performance, 18, 530-549.

Mack, A., Klein, L., Hill, J., \& Palumbo, D. (1989). Apparent motion: Evidence of the influence of shape, slant, and size on the correspondence process. Perception \& Psychophysics, 46, 201-206.

Merigan, W. H., Byrne, C. E., Maunsell, J. H. R. (1991). Does pri- mate motion perception depend on the magnocellular pathway? Journal of Neuroscience, 11, 3422-3429.

Meyer, G. E., \& Maguire, W. M. (1977). Spatial frequency and the mediation of short-term visual storage. Science, 198, 524-525.

NAVON, D. (1976). Irrelevance of figural identity for resolving ambiguities in apparent motion. Journal of Experimental Psychology: Human Perception \& Performance, 2, 130-138.

ORLANSKY, J. (1940). The effect of similarity and difference in form on apparent visual movement. Archives of Psychology, 246, 1-85.

PANTLE, A. J., \& PeTersik, J. T. (1980). Effects of spatial parameters on the perceptual organization of a bistable motion display. Perception \& Psychophysics, 27, 307-312.

Pantle, A. J., \& Picciano, L. (1976). A multistable movement display: Evidence for two separate motion systems in human vision. Science, 193, 500-502.

Petersik, J. T. (1984). The perceptual fate of letters in two kinds of apparent movement displays. Perception \& Psychophysics, 36, 146150.

Petersik, J. T., \& Pantle, A. J. (1979). Factors controlling the competing sensations produced by a bistable stroboscopic motion display. Vision Research, 19, 143-154.

PIKLER, J. (1917). Sinnesphysiologische Untersuchungen [Physiological investigations of the senses]. Leipzig: J. A. Barth.

Ramachandran, V. S., \& Cavanagh, P. (1987). Motion capture anisotropy. Vision Research, 27, 97-106.

Ramachandran, V. S., \& INADA, V. (1985). Spatial phase and frequency in motion capture of random-dot patterns. Spatial Vision, 1 , 57-67.

RichaRDS, W., \& KAY, M. G. (1974). Local versus global stereopsis: Two mechanisms? Vision Research, 14, 1345-1347.

RitTer, A. D., \& BReITMEyeR, B. G. (1989). The effects of dichoptic and binocular viewing on bistable motion percepts. Vision Research, 29, 1215-1219.

ROSE, D., \& BLAKE, R. (1988). Mislocalization of diplopic images. Journal of the Optical Society of America A, 5, 1512-1521.

ScHOR, C. M., \& WoOD, I. (1983). Disparity range for local stereopsis as a function of luminance spatial frequency. Vision Research, 23, 1649-1654.

Shechter, S., Hochstein, S., \& Hillman, P. (1988). Shape similarity and distance disparity as apparent motion correspondence cues. $V i$ sion Research, 28, 1013-1021.

ShIPley, W. C., KenNEY, F. A., \& KING, M. E. (1945). Beta apparent movement under binocular, monocular, and interocular stimulation. American Journal of Psychology, 58, 545-549.

SPERLING, G. (1970). Binocular vision: A physical and neural theory. American Journal of Psychology, 83, 461-534.

TERNUS, J. (1926). Experimentelle Untersuchungen über phänomenale Identität [Experimental investigations of phenomenal identity]. Psychologische Forschung, 7, 81-136.

TYLER, C. W. (1983). Sensory processing of binocular disparity. In C. M. Schor \& K. J. Ciuffreda (Eds.), Vergence eye movements: Basic and clinical aspects (pp. 199-296). Sevenoaks, U.K.: Butterworth.

TYLER, C. W. (1990). A stereoscopic view of visual processing streams. Vision Research, 30, 1877-1895.

UlLMAN, S. (1979). The interpretation of visual motion. Cambridge, MA: MIT Press.

ULLMAN, S. (1980). The effect of similarity between line segments on the correspondence strength in apparent motion. Perception, 9, 617626.

WANDELL, B. A. (1995). Foundations of vision. Sunderland, MA: Sinauer Associates, Inc.

Werkhoven, P., Sperling, G., \& ChubB, C. (1993). The dimensionality of texture-defined motion: A single channel theory. Vision Research, 33, 463-485

Werkhoven, P., Sperling, G., \& Chubb, C. (1994). Perception of apparent motion between dissimilar gratings: Spatiotemporal properties. Vision Research, 34, 2741-2759.

Wertheimer, M. (1912). Experimentelle Studien über das Sehen von Bewegung [Experimental studies about the perception of motion]. Zeitschrift für Psychologie, 61, 161-265. 


\section{NOTE}

1. Pantle and Picciano (1976) allowed observers only two response options (group or element motion) and found more group-motion responses with polarity reversals than without. Dawson et al. (1994) and Kramer (1998) allowed a third response option ("simultaneity" or "no motion"). They found more group-motion responses with polarity reversals at short ISIs but found no difference between the reversed-and constant-polarity conditions at long ISIs. The effect of ISI, which is also to increase group-motion responses, may have swamped the effect of polarity reversals at long ISIs.

(Manuscript received October 20,1997; revision accepted for publication April 29, 1998.) 